\title{
Journal of MARINE RESEARCH
}

Volume 63, Number 2

\section{Basin-scale performance of a locally optimized marine ecosystem model}

\author{
by A. Oschlies ${ }^{1,2}$ and M. Schartau ${ }^{3}$
}

\begin{abstract}
A marine ecosystem model, that had previously been calibrated in a one-dimensional (1D) mode against observations at three time-series and process-study sites simultaneously, is coupled to a three-dimensional (3D) circulation model of the North and Equatorial Atlantic. Compared to an experiment with a previously employed subjectively tuned ecosystem model, the new 3D-model does not only reduce the model-data misfit at those locations at which observations entered the 1D optimization procedure, but also at an oligotrophic site in the subtropics that had not been considered in the 1D calibration. Basin-scale gridded climatological data sets of nitrate, surface chlorophyll, and satellite-derived primary production also reveal a generally lower model-data misfit for the optimized model. The most significant improvement is found in terms of simulated primary production: on average, primary production is about 2.5 times higher in the optimized model which primarily results from the inclusion of a phytoplankton recycling pathway back to dissolved inorganic nitrogen. This recycling pathway also allows for a successful reproduction of nonvanishing surface nitrate concentrations over large parts of the subpolar North Atlantic. Apart from primary production, the parameter optimization reduces root-mean-square misfits by merely $10-25 \%$ and remaining misfits are still much larger than observational error estimates. These residual misfits can be attributed both to errors in the physical model component and to errors in the structure of the ecosystem model, which an objective estimation of ecosystem model parameters by data assimilation alone cannot resolve.
\end{abstract}

1. Leibniz-Institut für Meereswissenschaften an der Universität Kiel, Kiel, Germany.

2. Present address: Southampton Oceanography Center, Southampton, United Kingdom. email: andreas.oschlies@soc.soton.ac.uk

3. Marine Sciences Research Center, SUNY, Stony Brook, New York, 11794, U.S.A. 


\section{Introduction}

In contrast to the motion of sea water, for which the governing equations are known and uncertainties in our understanding arise mainly from technical difficulties in solving these equations, the theoretical understanding of marine ecosystem dynamics is much less mature. As a result, a wide variety of empirical marine ecosystem models are available which can be, and have been, used to investigate the biological response to external forcing by the physical environment (Evans and Parslow, 1985; Fasham et al., 1990; Sarmiento et al., 1993; Oschlies and Garçon, 1999; Christian et al., 2002). All of these models contain a large number of generally poorly known parameters that usually describe rates which are difficult to measure and moreover tend to vary across taxa not resolved by the models. A promising strategy that has evolved is the calibration, or optimization, of these parameters against more easily available measurements, e.g. of standing stocks. So far, this approach has been applied predominantly to observational data sets available at individual timeseries and process-study sites (e.g., Matear, 1995; Fasham and Evans, 1995; Prunet et al., 1996a,b; Hurtt and Armstrong, 1996; Spitz et al., 1998, 2001; Fennel et al., 2001; Schartau et al., 2001]. Albeit some of these local studies achieved relatively good fits to the observations used in the optimization, it remains to be investigated to what extent such locally calibrated models are applicable to the global scale.

Hurtt and Armstrong (1999) first tried to simultaneously fit their ecosystem model to observations at two sites in the North Atlantic: the Bermuda Atlantic Time-series Study (BATS, 32N 64W) and the Ocean Weather Ship India (OWSI, 59N 19W). They found reasonable fits only when they assumed different formulations for growth limitation at the two sites. In two recent studies (Schartau and Oschlies, 2003a,b, hereafter referred to as SO03a and SO03b) we used data at three North Atlantic sites, namely from the North Atlantic Bloom Experiment (NABE, 47N 20W), and from BATS and OWSI, to simultaneously optimize another simple marine ecosystem model. At each individual site, the model-data misfit of the simultaneously optimized model solution was reduced with respect to the earlier subjectively tuned model. Here we investigate whether a similar improvement can also be found on the basin scale, i.e., for locations other than those used in the optimization procedure. The model performance is evaluated by a comparison with data from the oligotrophic site of the French EUMELI program in the eastern part of the subtropical gyre, with satellite ocean color data, and with climatological nutrient fields. As none of these data has been used in the optimization, they represent an independent validation data set.

The paper is organized as follows: Section 2 gives a brief description of the coupled ecosystem-circulation model, with details of the ecosystem model equations deferred to the Appendix. A local evaluation at the sites used for the original optimization of the 1D model and of an independent site in the oligotrophic subtropical gyre is presented in Section 3. In Section 4 we use gridded climatological data sets of nutrients, surface chlorophyll, and satellite-derived primary production to evaluate the optimized model on the basin scale. Results are summarized in Section 5, and a concluding section ends the paper. 

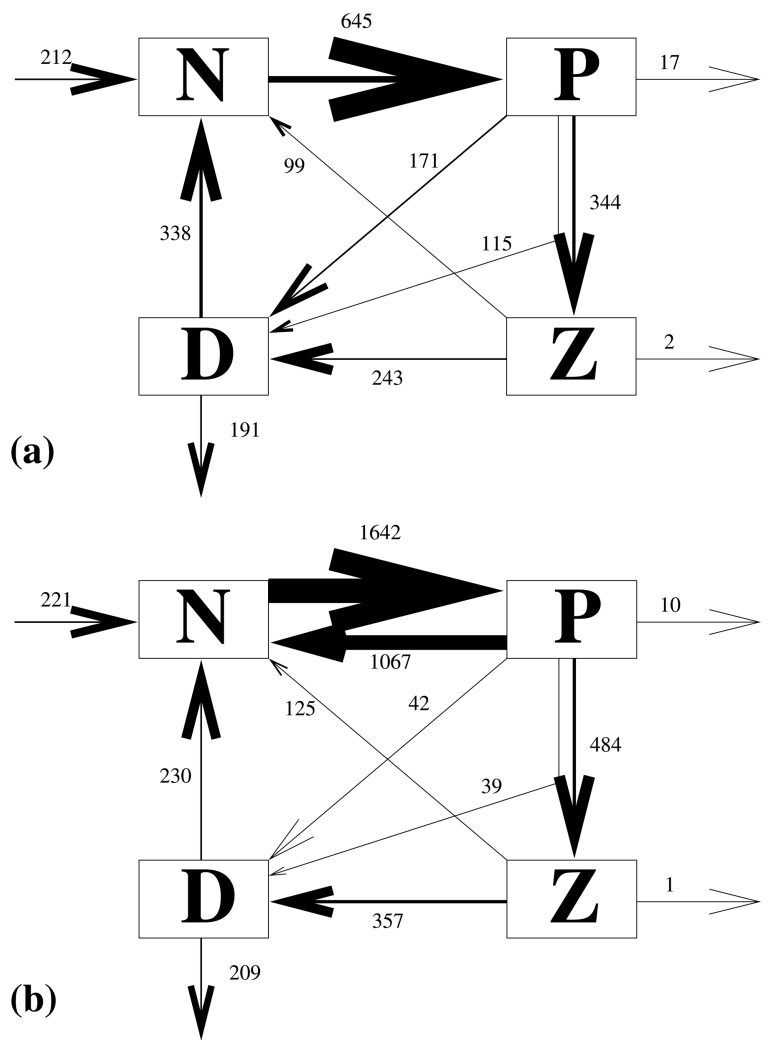

Figure 1. 5-year mean nitrogen fluxes averaged from $13 \mathrm{~S}$ to $63 \mathrm{~N}$ and over the top $126 \mathrm{~m}$ for (a) the standard ecosystem model as described by Oschlies and Garçon (1999) and (b) the optimized model version of Schartau and Oschlies (2003a). Units are $\mathrm{mmol} \mathrm{m}^{-2} \mathrm{yr}^{-1}$ and the arrow thickness is approximately proportional to the associated flux.

\section{Model}

Two versions of a simple nitrogen-based four-compartment ecosystem model are used in this study (Fig. 1). The standard model is identical to the one described by Oschlies and Garçon (1999), the optimized model is that described by SO03a. Its differences with respect to the standard model are the optimized parameter values, the inclusion of a temperature dependence of all remineralization rates, a quadratic phytoplankton mortality and a linear loss from phytoplankton back to the dissolved inorganic nitrogen (DIN) pool, and an empirical variable chlorophyll-to-nitrogen ratio after Cloern et al. (1995). Both ecosystem models are coupled to the same circulation model which covers the North Atlantic between $15 \mathrm{~S}$ and $65 \mathrm{~N}$ at a resolution of $1 / 3$ times $2 / 5$ degrees meridionally and zonally, respectively. There are 37 vertical levels with 11 levels resolving the upper $150 \mathrm{~m}$. Vertical mixing is modeled by a turbulent kinetic energy (TKE) closure scheme (Gaspar et al., 1990) tuned to closely match observational estimates of diapycnal diffusion derived 
from a tracer-release experiment in the main thermocline of the eastern subtropical North Atlantic (Ledwell et al., 1993; 1998). Atmospheric forcing consists of "climatological" monthly mean wind-stress and heat-flux fields derived from the years 1989 to 1993 of the reanalysis project carried out at the European Centre for Medium-Range Weather Forecasts (ECMWF) (Gibson et al., 1997). Freshwater fluxes are parameterized by restoring surface salinity to observed monthly means taken from the Levitus et al. (1994) atlas. To account for water mass transformation outside the North Atlantic model domain, temperature, salinity, and nitrate are restored to climatological data in buffer zones ( 5 grid points wide) at the closed northern and southern boundaries.

The 1D model configurations used by SO03a during the optimization procedure were forced by mixing coefficients, irradiance, and temperature profiles taken from a 3D simulation that had been run under daily atmospheric forcing over the period 1989 to 1993. This same set-up is used here for the 3D model to allow for a direct comparison of 1D and $3 \mathrm{D}$ results at the respective optimization sites. Starting from a spun-up state of the physical model, a two-year spin up is performed for the coupled ecosystem-circulation model before the actual 5-year analysis period begins. This 1D-3D comparison extends over the top $400 \mathrm{~m}$. To evaluate the 3D model also at greater depths, where adjustments of the nutrient fields to changes in the ecosystem model are slower, a second run was integrated over a 20-year period, using monthly-mean "climatological" atmospheric forcing computed from the 1989-1993 period. All comparisons among the 3D standard ecosystem model and the $3 \mathrm{D}$ version of the optimized model in this paper use the last five years of this 20-year run.

The relevant equations for the two ecosystem model configurations can be found in the Appendix, the associated parameter values for the two model configurations are given in Table 1.

\section{Local evaluation}

\section{a. $3 D$ model results at sites of the $1 D$ optimization}

A first test of the applicability of our locally optimized ecosystem model to basin or global scales is to evaluate the model-data misfit of the 3D model at the sites used in the 1D optimization process. Table 2 reveals that, compared to the standard model, the optimized model indeed shows a reduction in the model-data misfit for 11 out of 15 data types at the three sites. Except for zooplankton, for which very few observations were available (see SO03a), all variables show an overall decrease of the model-data misfit. With respect to the standard configuration, the largest relative reduction in the 3D model's model-data misfits is achieved for PON (on average by 34\%) and primary production (on average by 20\%) whereas DIN and chlorophyll misfits are on average reduced by merely $8 \%$ and $3 \%$, respectively. This mainly reflects that the optimal parameter values favor a model solution with increased primary production rates and, at the same time, smaller PON (and, in particular, zooplankton) biomass at these sites (see SO03b). The existence of a rapid 
Table 1. Parameters of the two ecosystem model configurations.

$\begin{array}{llcl}\text { Parameter } & \text { Symbol } & \begin{array}{c}\text { Standard } \\ (\text { OG99 })\end{array} & \begin{array}{c}\text { Optimized } \\ \text { (SO03) }\end{array}\end{array}$

Integration method for daily growth rate EP85 $\quad$ EP85

Initial slope of P-I curve

Photosynthetically active ratiation

$\begin{array}{crr} & \text { EP85 } & \text { EP85 } \\ \alpha & 0.025 & 0.256 \\ & & \\ \text { PAR } & 0.43 & 0.43 \\ & & \\ k_{w} & 0.04 & 0.04 \\ & & \\ k_{c} & 0.03 & 0.047 \\ & & \\ a & 0.6 & 0.27 \\ b & 1.066 & 1.066 \\ c & 1.0 & 1.0\end{array}$
day $^{-1} /\left(\mathrm{W} \mathrm{m}^{-2}\right)$

Light attenuation due to water

Light attenuation by phytoplankton

Maximum growth rate parameters
$K_{1}$
0.5
0.7
$\begin{array}{ll}\mu_{P} & 0.03\end{array}$
$0.04 \times b^{c T}$
$\mu_{P}^{*}$
0.025

$\mathrm{m}^{-1}$

Quadratic mortality rate

\section{Zooplankton (Z) Coefficients}

$\begin{array}{lcrcc}\text { Assimilation efficiency } & \gamma_{1} & 0.75 & 0.925 & \\ \text { Maximum grazing rate } & g & 2.0 & 1.575 & \mathrm{day}^{-1} \\ \text { Prey capture rate } & \epsilon & 1.0 & 1.6 & \left(\mathrm{mmol} \mathrm{m}^{-3}\right)^{-2} \mathrm{day}^{-1} \\ \text { (Quadratic) mortality } & \mu_{Z} & 0.20 & 0.34 & \left(\mathrm{mmol} \mathrm{m}^{-3}\right)^{-1} \mathrm{day}^{-1} \\ \text { Excretion } & \gamma_{2} & 0.03 & 0.01 \times b^{c T} & \mathrm{day}^{-1}\end{array}$

Detrital (D) Coefficients

$\begin{array}{lrrrc} & & & 0.048 \times & \\ \text { Remineralization rate } & \mu_{D} & 0.050 & b^{c T} & \text { day }^{-1} \\ \text { Sinking velocity } & w_{s} & 5.0 & 18.0 & \mathrm{~m} \mathrm{day}^{-1}\end{array}$

OG99 stands for Oschlies and Garçon (1999), SO03 for Schartau and Oschlies (2003a), and EP85 for Evans and Parslow (1985).

In the optimized version, all remineralization rates $\left(\mu_{P}, \gamma_{2}, \mu_{D}\right)$ include the same temperaturedependent function $b^{c T}$ that is also applied to the maximum growth rate $a$.

recycling loop in the optimized model is responsible for enhanced primary production associated mainly with nutrients recycled within the euphotic zone rather than with new nutrient from below. This reduction in the model's $f$-ratio (from a basin-averaged value of 0.33 to 0.13 ) allows for an increase in simulated primary production without a corresponding increase in biomass, new production, export flux, or grazing pressure. Note, however, that the standard run shows in fact a smaller misfit for three out of five variables at the 
Table 2. Model-data RMS misfits.

CHL

DIN

PP

PON

$\mathrm{ZOO}$

Site $\quad\left(\mathrm{mg} \mathrm{m}^{-3}\right)$

$\left(\mathrm{mmol} \mathrm{m}{ }^{-3}\right)$

$\left(\mathrm{mg} \mathrm{C} \mathrm{m}{ }^{-3} \mathrm{~d}^{-1}\right)$

(mmol $\mathrm{N} \mathrm{m}^{-3}$ )

$\left(\mathrm{mmol} \mathrm{N} \mathrm{m}{ }^{-3}\right.$ )

$\begin{array}{lll}\text { BATS } & 0.070 & 0.394 \\ \text { NABE } & 0.292 & 2.974 \\ \text { OWSI } & 0.273 & 5.007\end{array}$

ID optimized experiment

$3 D$ standard experiment ${ }^{a}$

$\begin{array}{llllll}\text { BATS } & \mathbf{0 . 2 0 2} & \mathbf{2 . 1 1 1} & 3.406 & 0.299 & \mathbf{0 . 1 2 2} \\ \text { NABE } & 0.363 & 4.189 & 12.83 & 0.855 & 0.177 \\ \text { OWSI } & 0.257 & 4.613 & 8.976 & 0.528 & 0.286\end{array}$

$3 D$ optimized experiment $t^{b}$

$\begin{array}{llllll}\text { BATS } & 0.233 & 2.244 & \mathbf{2 . 4 3 3} & \mathbf{0 . 1 7 6} & 0.159 \\ \text { NABE } & \mathbf{0 . 3 1 5} & \mathbf{3 . 9 3 1} & \mathbf{1 1 . 1 3} & \mathbf{0 . 6 1 6} & 0.283 \\ \text { OWSI } & \mathbf{0 . 2 2 5} & \mathbf{3 . 5 6 2} & \mathbf{7 . 3 6 4} & \mathbf{0 . 3 5 2} & \mathbf{0 . 2 3 3}\end{array}$

$3 D$ subjectively tuned model ${ }^{c}$

$\begin{array}{llllll}\text { BATS } & 0.251 & 2.463 & 3.359 & 0.280 & 0.147 \\ \text { NABE } & 0.399 & 4.433 & 12.58 & 0.778 & \mathbf{0 . 1 4 6} \\ \text { OWSI } & 0.387 & 4.861 & 10.11 & 0.560 & 0.243\end{array}$

Root-mean-square (RMS) misfits are computed for model runs using actual daily forcing over the 5-year period 1989-1993 for the uppermost 15 model-levels $(0-411 \mathrm{~m})$ from monthly means for each month for which observations are available (see Schartau and Oschlies (2003a)).

CHL is chlorophyll $a$, DIN is dissolved inorganic nitrogen, PP is primary production, PON is particulate organic nitrogen, and ZOO is zooplankton biomass.

${ }^{a}$ ecosystem model described by Oschlies and Garçon (1999),

${ }^{b}$ ecosystem model optimized by Schartau and Oschlies (2003a),

${ }^{c}$ subjectively tuned ecosystem model of Oschlies (2001).

For each station and each variable, the smallest of the values for the three 3D simulations is printed in bold.

BATS site, where the RMS misfits are typically two to three times larger for the 3D simulations than for the optimized 1D model. This indicates that the assumptions made in the 1D optimizations, in particular the neglect of laterally advected gradients in biogeochemical tracer concentrations, are inappropriate at this site. The 1D optimization will erroneously interpret advectively generated tracer changes as biotically generated ones, and will thereby tend to correct for the neglect of advective transports by changing the biological model parameters. In contrast, the magnitude of the RMS misfits at NABE and OWSI is very similar for the $1 \mathrm{D}$ and $3 \mathrm{D}$ model results of the optimized model, albeit consistently larger than at the BATS site where the absolute tracer concentrations are also smaller. Reasons for the particularly large difference between 1D and 3D model-data 
misfits at BATS are the stronger lateral property gradients, and the associated lateral transport of nutrients and biomass both by the mean flow and by eddies along the margins of the subtropical gyre (Williams and Follows, 1998; Oschlies, 2002). Eddies and lateral advection are also present at the NABE and OWSI sites, but the environment is statistically more homogeneous and associated physical sinks and sources of nutrients are, on annual and longer time scales, by far dominated by vertical mixing within the deep winter mixed layer.

\section{b. Comparison against independent station data}

Although the three sites used to optimize the ecosystem model already belong to different biogeochemical provinces as introduced by Longhurst (1998), they all lie north of $30 \mathrm{~N}$ and do not cover tropical, coastal, or fully oligotrophic regions of the North Atlantic. To test how well the locally calibrated model is applicable to other biogeochemical regimes, we use data from the French Eutrophic, Mesotrophic, Oligotrophic (EUMELI) program with observations taken during five cruises between July 1989 and December 1992 at about 20N in the eastern subtropical Atlantic (Morel, 2000). Of most interest to the present study is the oligotrophic site near $21 \mathrm{~N}, 31 \mathrm{~W}$ because it is nearest to the center of the subtropical gyre where the standard model configuration was found to display the largest systematic underestimation of primary production (Oschlies et al., 2000).

Levels of simulated primary production at the oligotrophic EUMELI site have indeed increased by more than an order of magnitude in the optimized version of the model (Fig. 2). Typical values are now $2.4 \mathrm{mmol} \mathrm{N}$ day $^{-1}$ compared to less than $0.2 \mathrm{mmol} \mathrm{N}$ day ${ }^{-1}$ in the standard version and about $4 \mathrm{mmol} \mathrm{N} \mathrm{day}^{-1}$ in the observations (Morel, 2000) when a molar N:C conversion factor of 16:106 is employed. Accordingly, the 1D optimization at the BATS, NABE, and OWSI sites has thus reduced the 3D model-data misfit for primary production at the oligotrophic EUMELI site by more than $50 \%$. A similar, albeit somewhat smaller, reduction in the model-data misfit is found for chlorophyll and for zooplankton (Figs. $2 \mathrm{~b}$ and $2 \mathrm{c}$ ).

The local validation of the optimized model at the oligotrophic EUMELI site with data independent from those used in the optimization process is encouraging. Nevertheless, for a more rigorous evaluation of the potential benefits of the $1 \mathrm{D}$ optimized model version in a 3D modeling context, we will have to look at results on the basin scale as well.

\section{Basin-scale evaluation}

\section{a. Ecosystem dynamics}

Basin-average nitrate supply into, and particle export out of, the upper $126 \mathrm{~m}$ differ only by about $5 \%$ (i.e., by $0.01 \mathrm{~mol} \mathrm{~N} \mathrm{~m}^{-2} \mathrm{yr}^{-1}$ ) between the two model versions. Regional differences are also relatively small, with some tendency to enhanced export production (by about 20\%) over the subpolar gyre and in the eastern part of the tropical Atlantic in the optimized version (Fig. 3). Although this underlines the strong control of nutrient fluxes by 


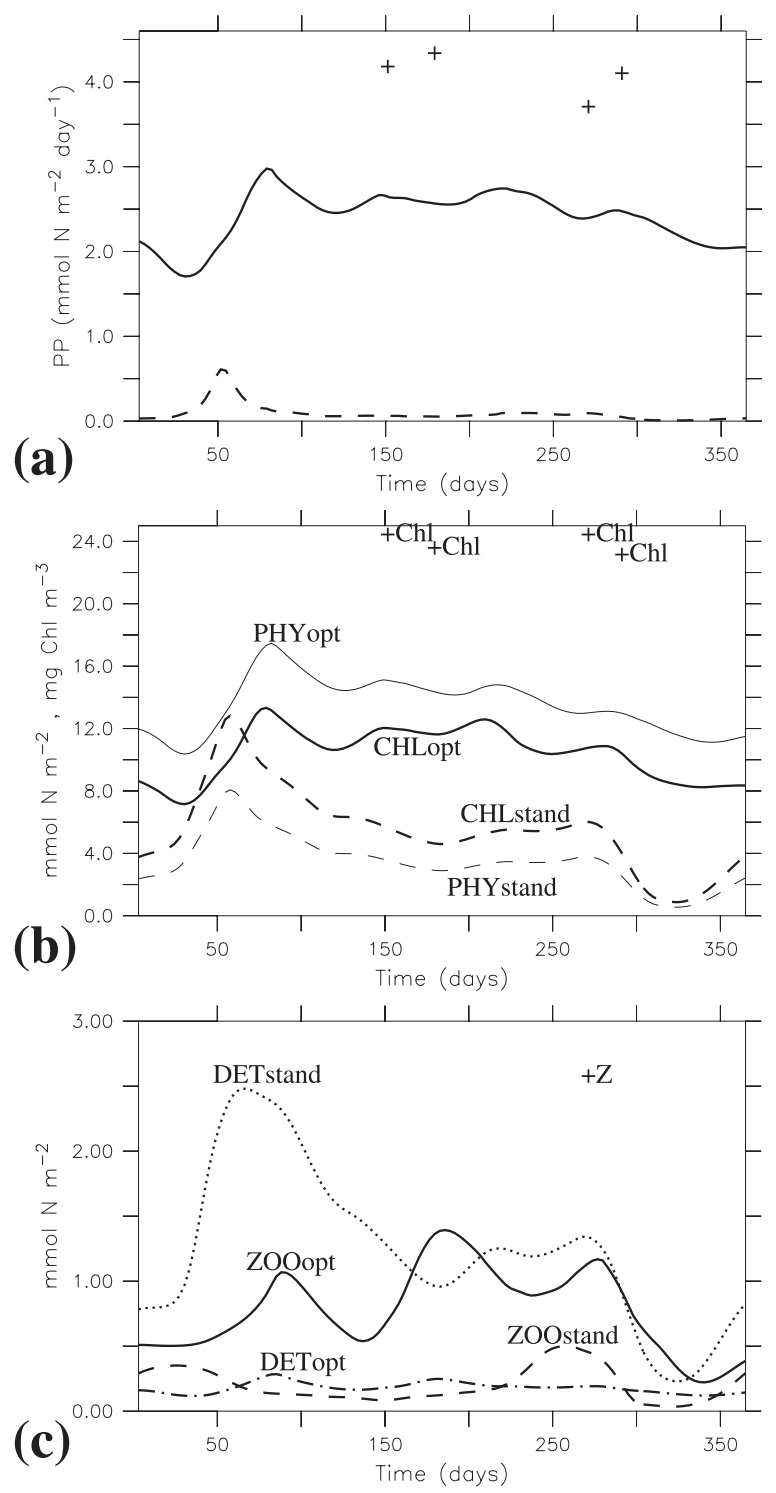

Figure 2. (a) Annual cycle of simulated primary production at the oligotrophic EUMELI site (21N, $31 \mathrm{~W}$ ) by the optimized model version (solid line) and by the standard configuration (dashed line). Crosses indicate ${ }^{14} \mathrm{C}$ primary production measurements (Morel, 2000) converted to nitrogen units by a molar C:N ratio of 6.625. (b) Simulated vertical integrals of phytoplankton and chlorophyll for the optimized model version (thin and thick solid lines, respectively) and for the standard model (thin and thick dashed lines). While the standard configuration uses a constant chlorophyllto-nitrogen ratio of $1.59 \mathrm{mg} \mathrm{Chl}(\mathrm{mmol} \mathrm{N})^{-1}$, the optimized version employs a variable ratio based on the empirical fit of Cloern et al. (1995) which, at this site, yields average ratios less then $1 \mathrm{mg} \mathrm{Chl}(\mathrm{mmol} \mathrm{N})^{-1}$. Crosses denote observations taken during the French EUMELI programme (Morel, 2000). (c) Annual cycle of zooplankton stocks simulated by the optimized model (solid line), zooplankton in the standard model (dashed line), detritus in the optimized model (dasheddotted line), and detritus in the standard model (dotted line). One zooplankton measurement taken during the French EUMELI program (Morel, 2000) and converted from carbon to nitrogen by the molar ratio of 6.625 is indicated by the cross, a second measurement of $4.65 \mathrm{mmol} \mathrm{N} \mathrm{m}^{-2}$ is beyond the upper limit of the ordinate. Results for the standard model differ slightly from those shown for the same model by Oschlies and Garçon (1999) because of a different atmospheric forcing used. 

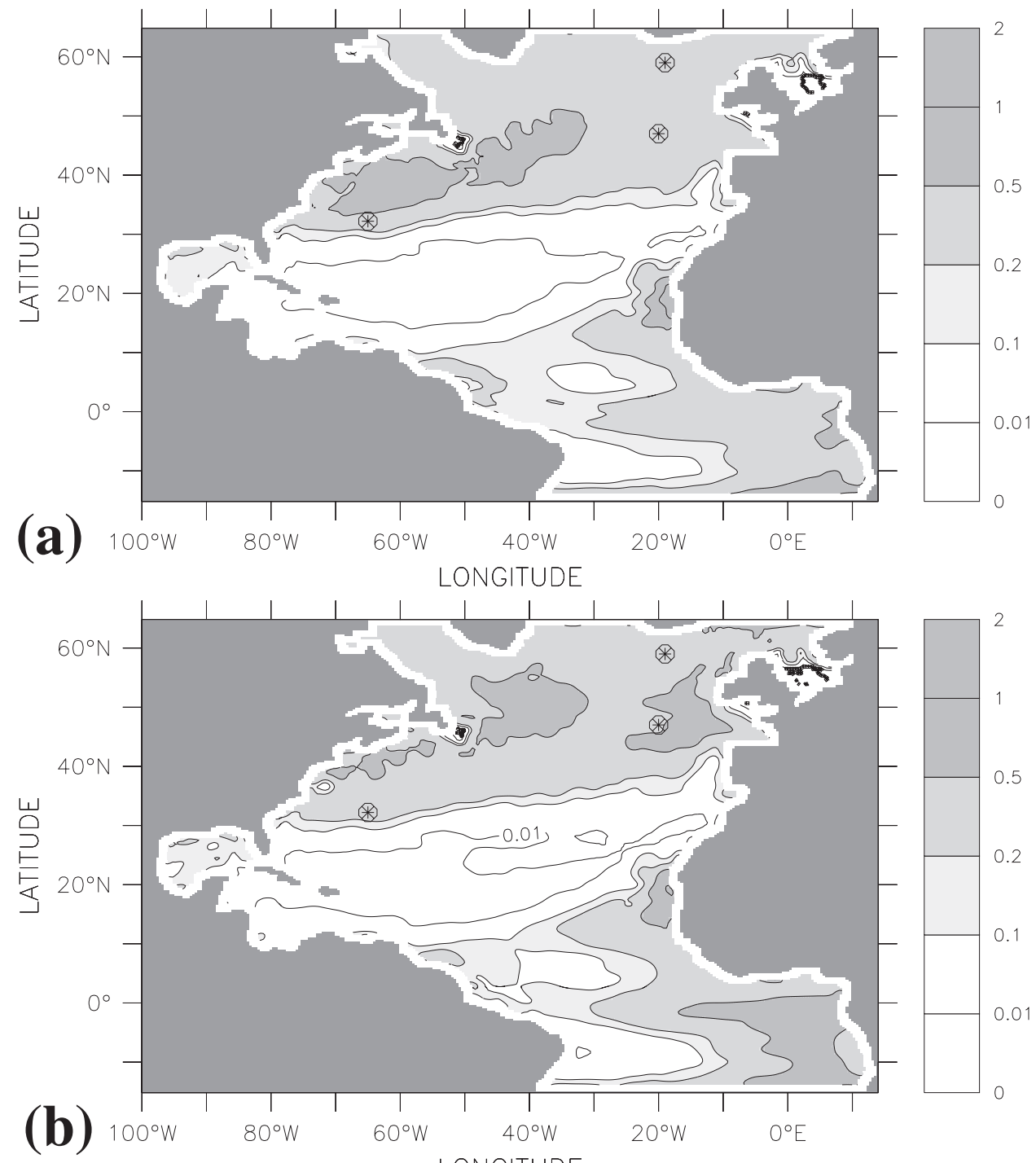

LONGITUDE

Figure 3. 5-year mean simulated export of particulate organic nitrogen out of the upper $126 \mathrm{~m}$ for (a) the standard ecosystem model (Oschlies and Garçon, 1999) and (b) the optimized model of Schartau and Oschlies (2003a). Units are $\mathrm{mol} \mathrm{N} \mathrm{m}^{-2} \mathrm{yr}^{-1}$. Symbols indicate the locations of the three sites at which the 1D model had been calibrated.

physical transport processes, which are identical for the two models, this close similarity is, at first sight, still surprising given that sinking velocities differ more than threefold ( $5 \mathrm{~m} \mathrm{day}^{-1}$ in the standard experiment, $18 \mathrm{~m}$ day $^{-1}$ in the optimized model, see Table 1). However, because of the temperature dependence of the remineralization rate in the 
optimized model version, detritus also remineralizes faster than in the standard model (three times faster at a temperature of $17^{\circ} \mathrm{C}$, two times faster at $11^{\circ} \mathrm{C}$ ). This ensures that, at least in the warmer upper layers, the optimization has little impact on the effective nitrogen loss due to particle export. Simulated primary production, on the other hand, is more than 2.5 times larger in the optimized model version. Although production rates are higher everywhere than in the standard run, relative increases are largest (by more than a factor of 100) in the oligotrophic subtropical gyre (Fig. 4).

Overall, meridional differences in primary productivity are much reduced to a range from $50 \mathrm{gC} \mathrm{m}^{-2} \mathrm{yr}^{-1}$ in the subtropics to $150 \mathrm{gC} \mathrm{m}^{-2} \mathrm{yr}^{-1}$ in mid latitudes in the optimized model compared to a range of less than $1 \mathrm{gC} \mathrm{m}^{-2} \mathrm{yr}^{-1}$ to about $100 \mathrm{gC} \mathrm{m}^{-2} \mathrm{yr}^{-1}$ in the standard model. The optimized model results are generally much closer to the satellite-derived estimates of primary production by Antoine et al. (1996). Still, the model seems to overestimate primary production along the equator and underestimates it in coastal areas like the European Shelf and over the northern half of the subpolar gyre. A similar underestimation of the annual primary production was already identified for the OWSI site in the 1D optimized model (SO03b) and mainly reflects a shortened season for algal growth. At this site, the initialization of the spring bloom is significantly delayed, which may result from the neglect of the diel mixed layer cycle in the model physics (OS03b).

The increase in simulated primary production is mainly a result of the added fast recycling path from phytoplankton directly back to the DIN pool. While the standard configuration partitions the recycling of nitrogen approximately equally among grazing and a flux from phytoplankton directly to the detritus compartment, the optimized version recycles about two thirds of the primary production immediately back to the nutrient compartment (Fig. 1). The increase in simulated primary production is fueled mainly by nutrients regenerated within the euphotic zone and not by new nutrients coming from below. Accordingly, there is no associated increase in particle export out of the euphotic zone, i.e., the ratio of particle flux to the vertically integrated primary production decreases. This ratio is often called export ratio, and annual mean maps are shown for both model configurations in Figure 5. Reductions in the export ratio on switching from the standard model to the optimized model are most dramatic in the subtropical gyre (from values even exceeding 1.0, indicative of lateral convergence and subsequent export of particulate organic matter, to values of less than 0.1 ). On the basin average and in steady state, the export ratio equals the so-called $f$-ratio which describes the ratio of production fueled by nutrient from outside the euphotic zone to total primary production. Its basin-averaged value decreases from 0.33 in the standard run to 0.13 for the optimized model.

In the optimized version, most of the photosynthetically fixed organic nitrogen that is not immediately recycled back from the phytoplankton compartment to the DIN pool is channeled through the zooplankton compartment with phytoplankton loss directly to detritus (e.g., mortality) playing only a minor role. On average, less than $3 \%$ of the total phytoplankton losses go directly into the detritus compartment, and even locally 

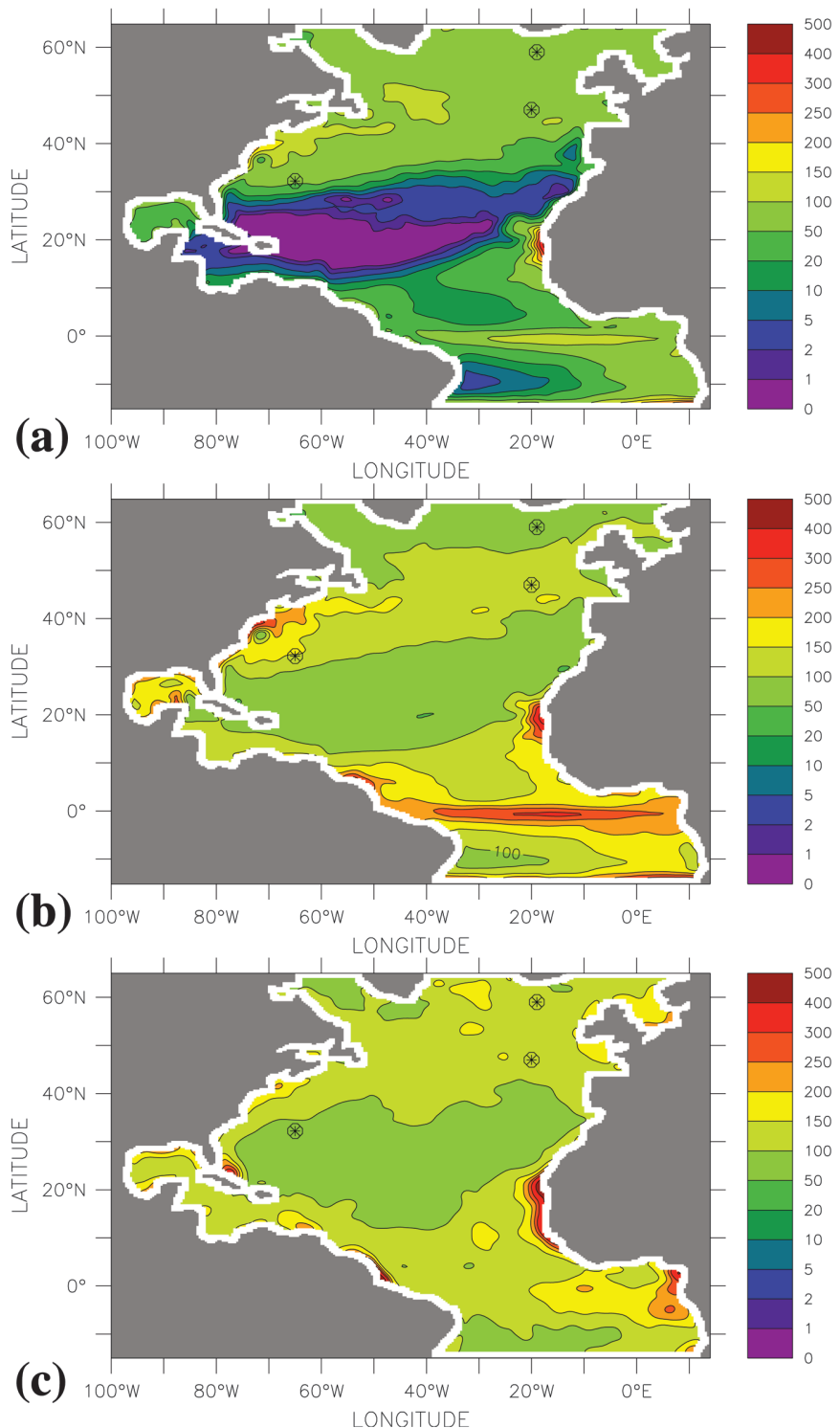

Figure 4. 5-year mean primary production (a) as simulated by the standard ecosystem model (Oschlies and Garçon, 1999) and (b) by the optimized model of Schartau and Oschlies (2003a). Also shown in (c) is the primary production estimated from satellite ocean color data by Antoine $e t$ al. (1996). Units are $\mathrm{gC} \mathrm{m}^{-2} \mathrm{yr}^{-1}$.

this portion does not exceed 6\%. In the subtropical gyre, more than $90 \%$ of the simulated phytoplankton loss occurs via the direct recycling loop to DIN, whereas in subpolar regions at least $60 \%$ are channeled through the zooplankton compartment 

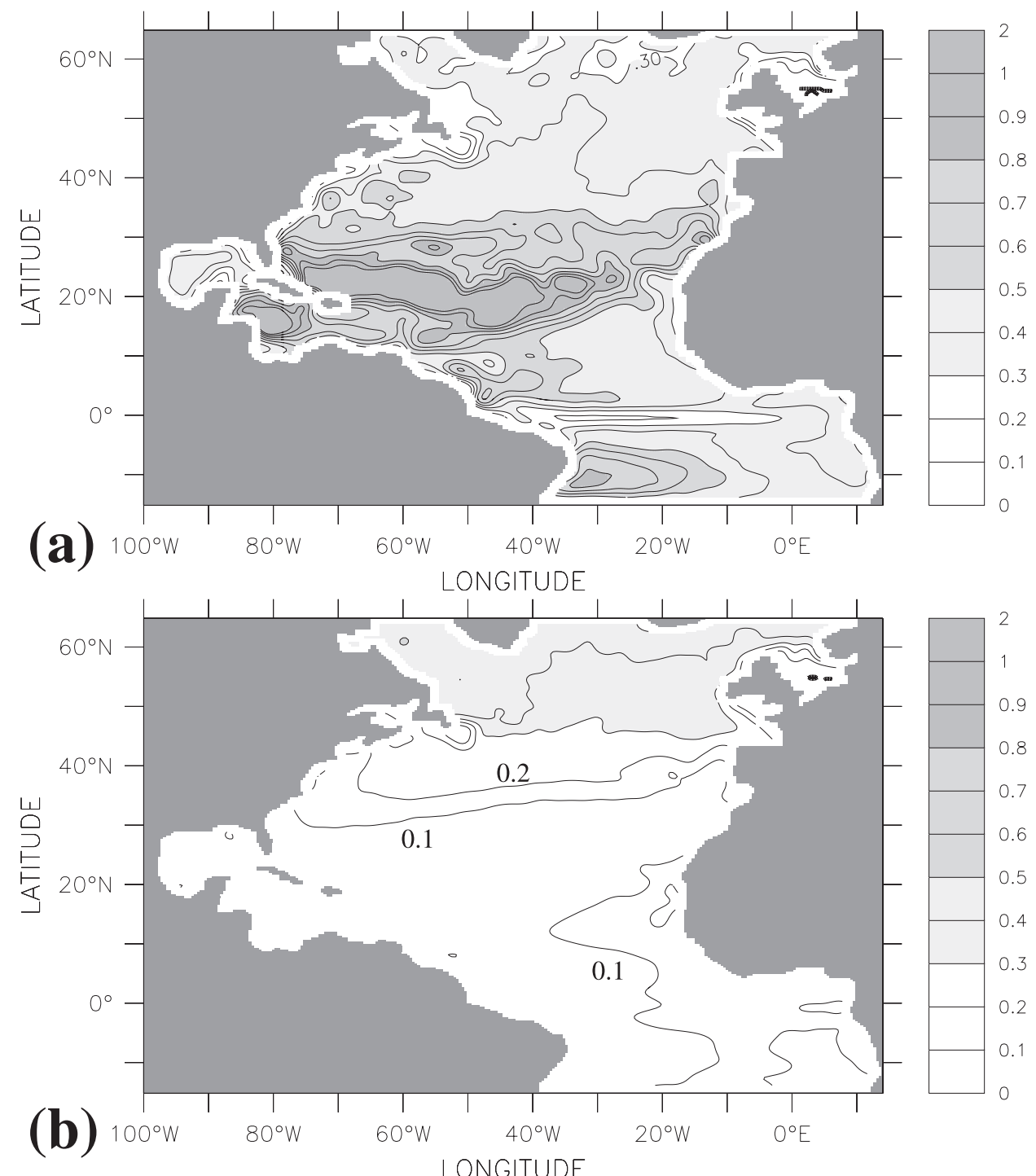

Figure 5. Simulated export ratio of the 5-year mean particulate organic matter export across the $126 \mathrm{~m}$ depth level to the vertically integrated primary production, (a) as simulated by the standard ecosystem model (Oschlies and Garçon, 1999) and (b) by the optimized model of Schartau and Oschlies (2003a). Export ratios larger than 1.0 in (a) in the subtropical gyre reflect lateral convergence of particulate organic matter within the euphotic zone and subsequent export out of it.

(Fig. 6). This is consistent with the interpretation of the rapid recycling loop as a parameterization of the microbial loop whereas the model's zooplankton tends to account less for microzooplankton (as is usually assumed in simple NPZD-type 


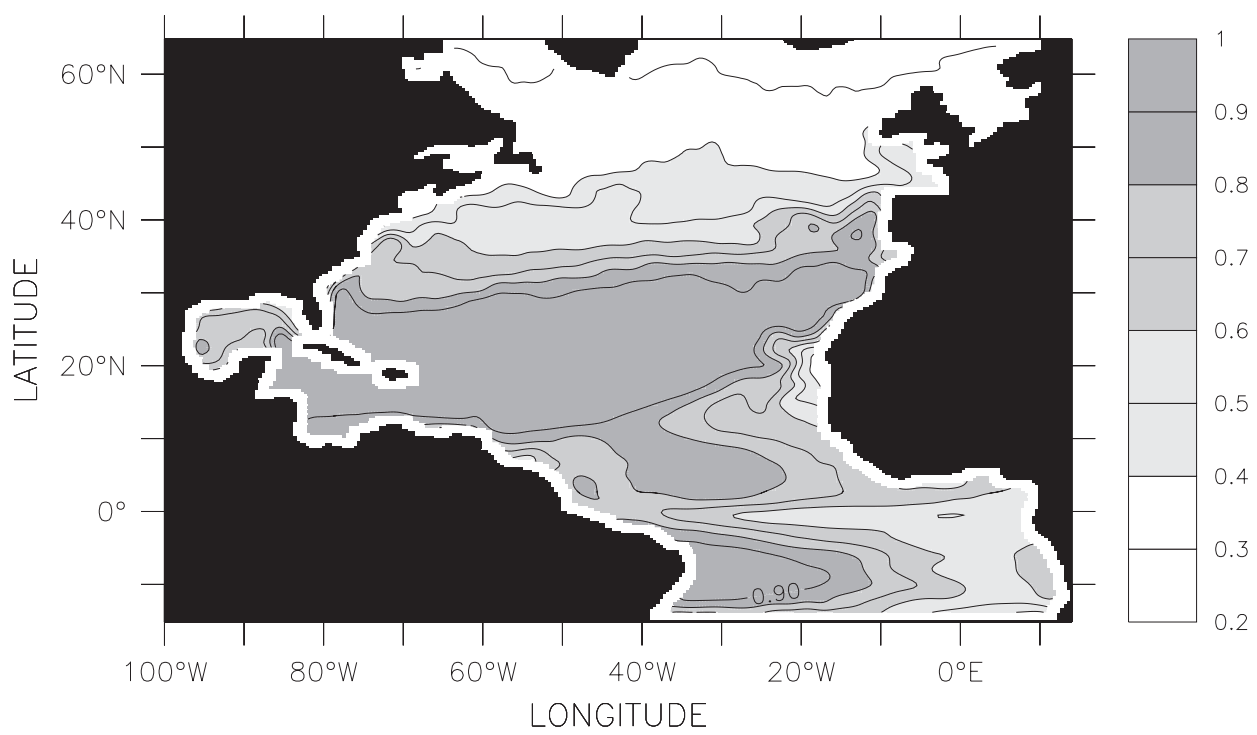

Figure 6. Ratio of the simulated 5-year mean phytoplankton loss integrated over the upper $126 \mathrm{~m}$ that is fluxed directly back to the dissolved inorganic nitrogen to the phytoplankton loss that is channeled through the zooplankton compartment.

ecosystem models) and more for the larger zooplankton that grazes the generally larger phytoplankton in the more eutrophic regions.

\section{b. Standing stocks}

Zonally averaged differences between simulated and data-based climatological nitrate (Conkright et al., 1994), also used to initialize the model, reveal substantial systematic model deficiencies (Fig. 7). Both the optimized and the standard ecosystem model considerably overestimate subsurface nitrate concentrations in the tropics. This "nutrient trapping" phenomenon has been identified in many models (e.g., Najjar et al., 1992) and is believed to be caused to a large extent by physical and numerical model errors (Matear and Holloway, 1995; Aumont et al., 1999; Oschlies, 2000). Here we find that the overestimate of nutrient concentrations is about $20 \%$ smaller in the optimized model version. Given that the sinking velocity of detritus is more than 3 times larger compared to the standard model whereas the temperature-dependent detritus remineralization rate in this depth (i.e., temperature) range is only about 1.5 to 2 times larger, a purely export-driven nutrient trapping should be reduced by about 30 to $50 \%$ on the decadal time scales considered here. The smaller reduction realized in the optimized model suggests that not more than half of the enhanced nutrient concentration can be attributed to errors in the export of particulate organic matter.

Overall, the global nitrate fields of the two model runs reveal a very similar correlation with the climatological estimate. The RMS deviation with respect to the climatology is 

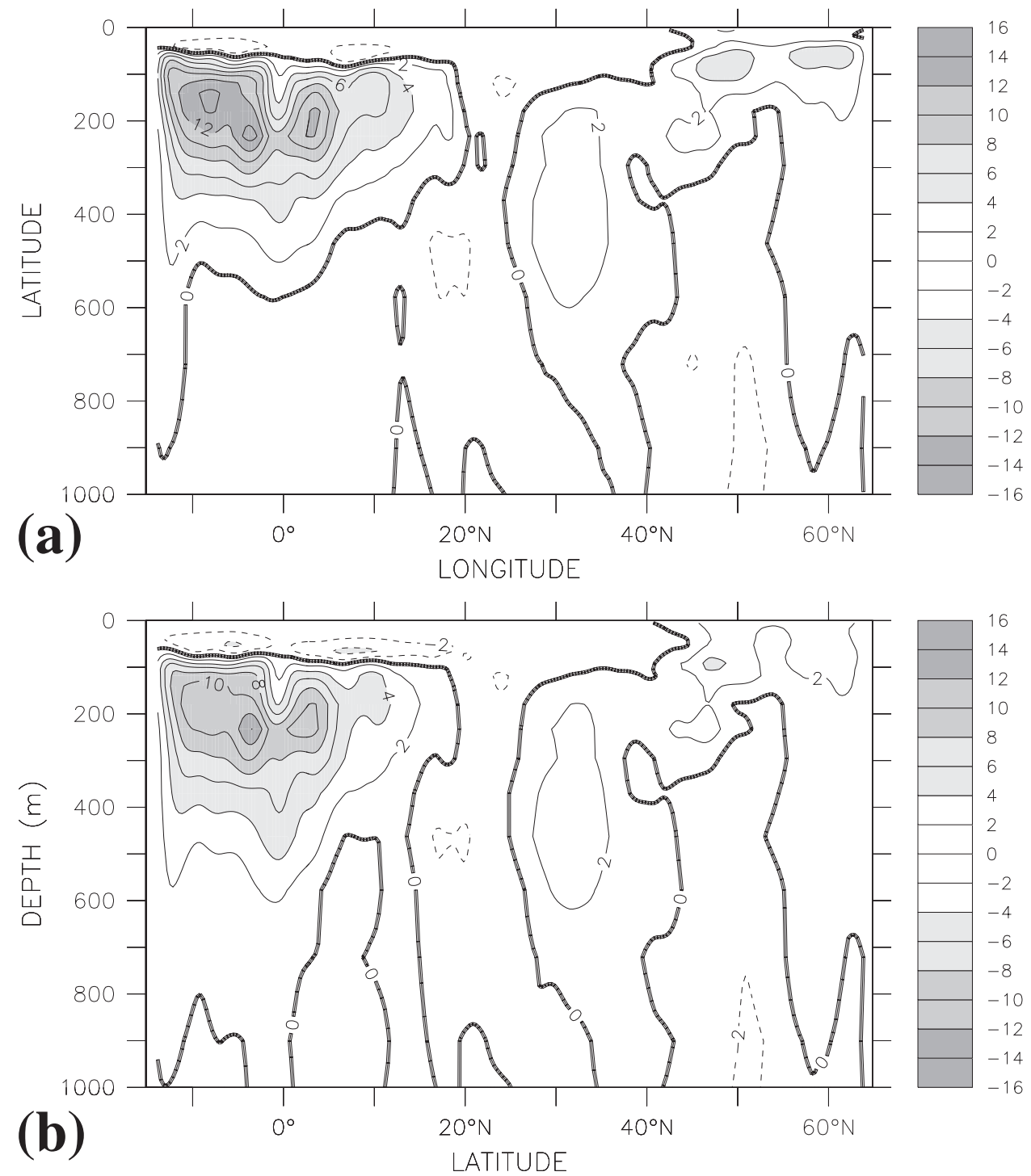

Figure 7. Zonally averaged deviations of simulated nitrate from the Conkright et al. (1994) nitrate climatology used to initialize the model. (a) For the standard model, and (b) for the optimized model. In both cases, model data are averaged over years 16-20 of the respective coupled simulation. Below $1000 \mathrm{~m}$ deviations are always smaller than $2 \mathrm{mmol} \mathrm{m}^{-3}$, and differences between the two model runs are very small during the 20 -year integration. Units are $\mathrm{mmol} \mathrm{m}^{-3}$.

only a few percent smaller for the optimized run $\left(2.16 \mathrm{mmol} \mathrm{m}^{-3}\right.$ versus $2.29 \mathrm{mmol} \mathrm{m}^{-3}$ in the standard run) when the entire depth range down to the ocean bottom is considered. Changes are more pronounced for the upper ocean which only can, on the decadal time 


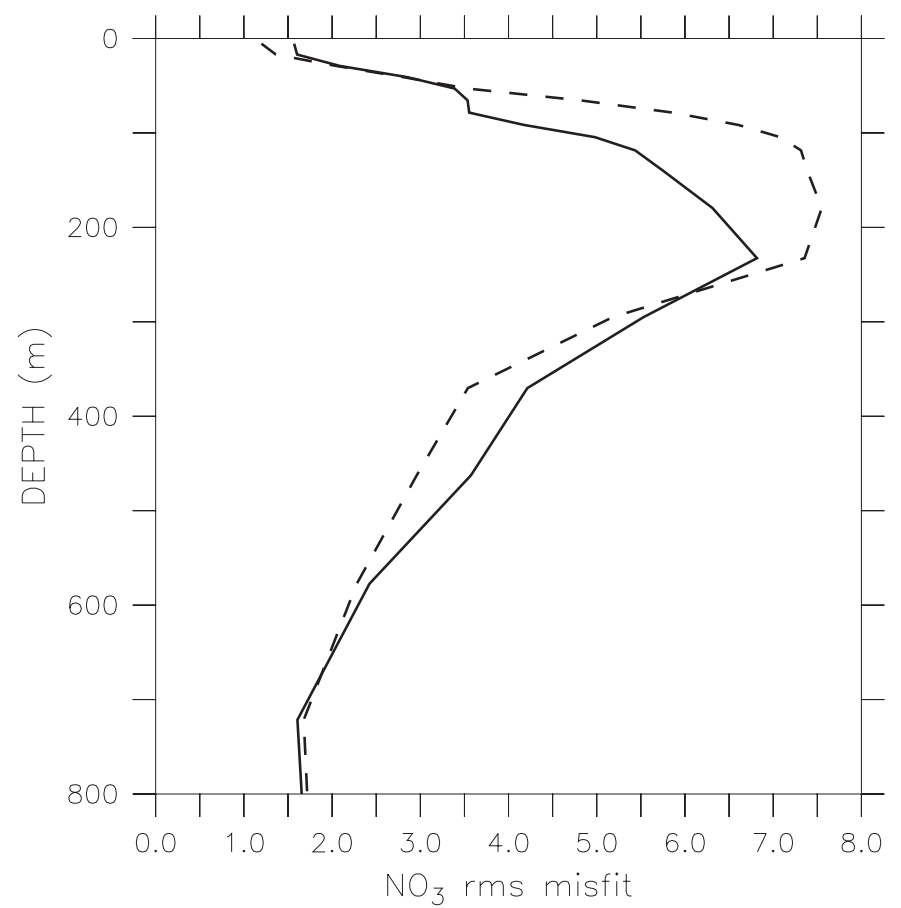

Figure 8. RMS deviation between simulated and climatological (Conkright et al., 1994) nitrate computed at each model depth level over the entire model domain. The solid line refers to the optimized model version, and the dashed line to the standard model.

scales considered here, be affected by changes in the ecosystem model configuration (Fig. 8). For the upper $126 \mathrm{~m}$, the RMS misfit of annual mean nitrate is $3.6 \mathrm{mmol} \mathrm{m}^{-3}$ in the optimized version, compared to $5.0 \mathrm{mmol} \mathrm{m}^{-3}$ in the standard configuration. Despite the $27 \%$ reduction in the surface nitrate misfit by the optimization, the remaining RMS misfit is still not much smaller than the mean nitrate concentration of the upper $126 \mathrm{~m}$ ( $4.6 \mathrm{mmol} \mathrm{m}^{-3}$ in the gridded data, $4.6 \mathrm{mmol} \mathrm{m}^{-3}$ in the optimized model run, and $5.4 \mathrm{mmol} \mathrm{m}{ }^{-3}$ in the standard run). Note, that particularly in the high latitudes, this misfit is likely affected by a seasonal bias of the nitrate climatology toward spring and summer observations.

We now consider maps of surface chlorophyll as additional independent validation data: One set includes data from the SeaWiFS satellite ocean color sensor (here data over the 5-year period September 1997 to 2002 are used), whereas the other set is a compilation of in-situ chlorophyll measurements by Conkright et al. (2002). A comparison of seasonal means interpolated onto the $1 / 3$ degree North Atlantic model grid reveals a relatively poor correlation of about 0.5 among the two data sets as well as a consistently lower variance in the Conkright et al. data set (Fig. 9). Note that this holds even though we have already eliminated coastal areas by accounting only for surface grid points below which the water 


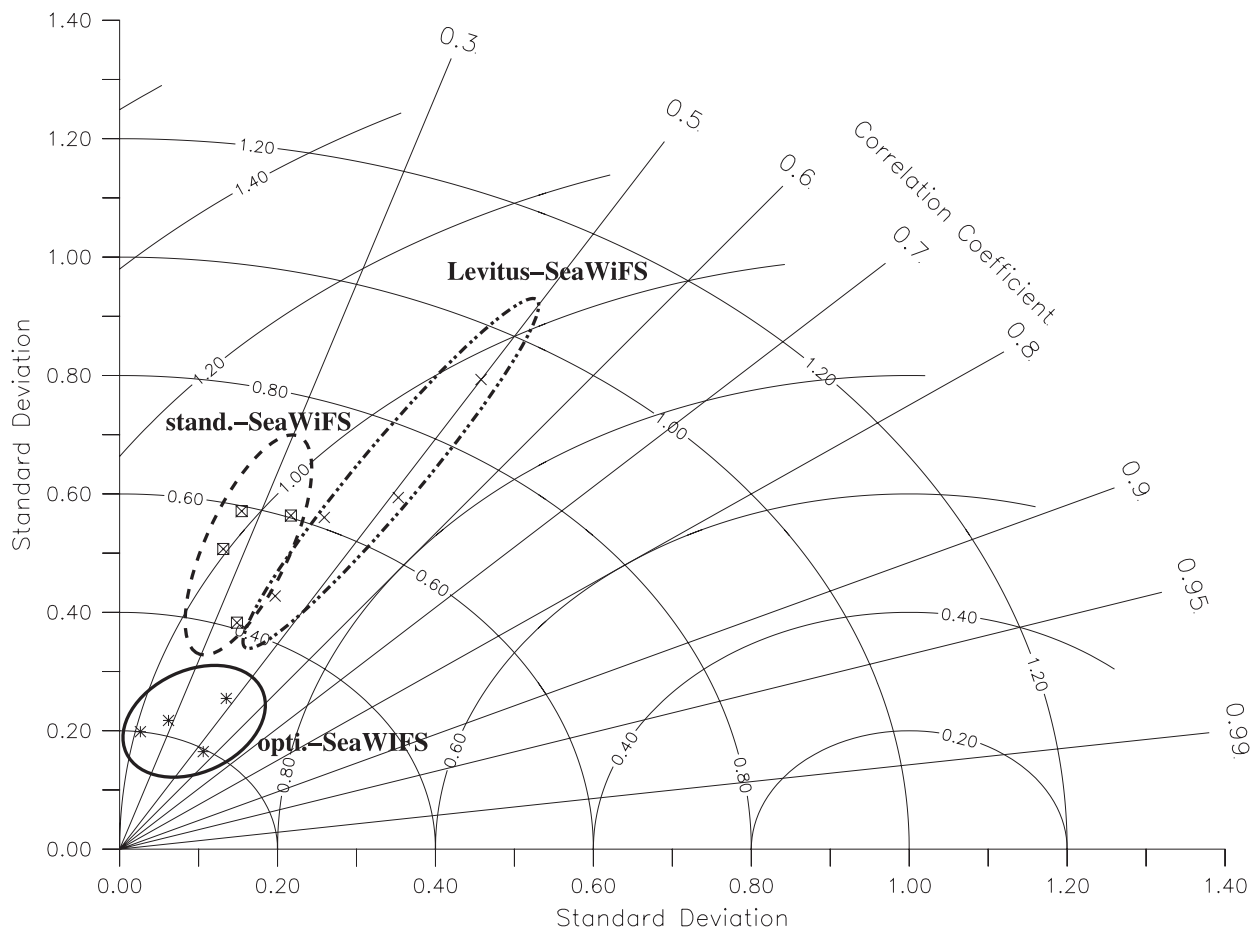

Figure 9. Taylor (2001) diagram of seasonally averaged surface chlorophyll derived from the standard and optimized model versions and from the Conkright et al. (2002) climatology with respect to the SeaWiFS-derived surface chlorophyll for the 5-year period September 1997 to 2002. All seasonal averages have been interpolated onto the same 1/3 degree North Atlantic model grid. To exclude coastal regions and shelf seas, only grid points with water depths exceeding $500 \mathrm{~m}$ are considered. All values are normalized by the standard deviation of the SeaWiFS data. The diagram is read as follows: The normalized standard deviation of a data set about the basin mean is the distance to the origin. The correlation with the SeaWiFS data is given by the azimuthal position, and the pattern RMS difference (the RMS difference after subtraction of the mean) is denoted by the circles centered at $(1,0)$. A data set in perfect agreement with the SeaWiFS chlorophyll data would be marked on the $x$-axis at standard deviation 1, correlation 1, and RMS error zero.

is more than $500 \mathrm{~m}$ deep. The correlation of surface chlorophyll simulated by the standard simulation with the SeaWiFS data is even smaller (about 0.3 ). Only a slightly better correlation is obtained for the optimized version on the expense of a much underestimated pattern variance. The optimized version also underestimates the temporal variability of the surface chlorophyll fields. The amplitude of the seasonal cycle is much reduced compared to the standard experiment and also with respect to the SeaWiFS data (Fig. 10). In particular, surface chlorophyll concentrations simulated by the optimized model are much too low during and after the spring bloom, remaining below $0.5 \mathrm{mg} \mathrm{Chl} \mathrm{m}^{-3}$ in the zonal average compared to zonal mean values of more than $1 \mathrm{mg} \mathrm{Chl} \mathrm{m}^{-3}$ in the SeaWiFS data. This reduction in the amplitude of the seasonal cycle in surface chlorophyll is only partly 

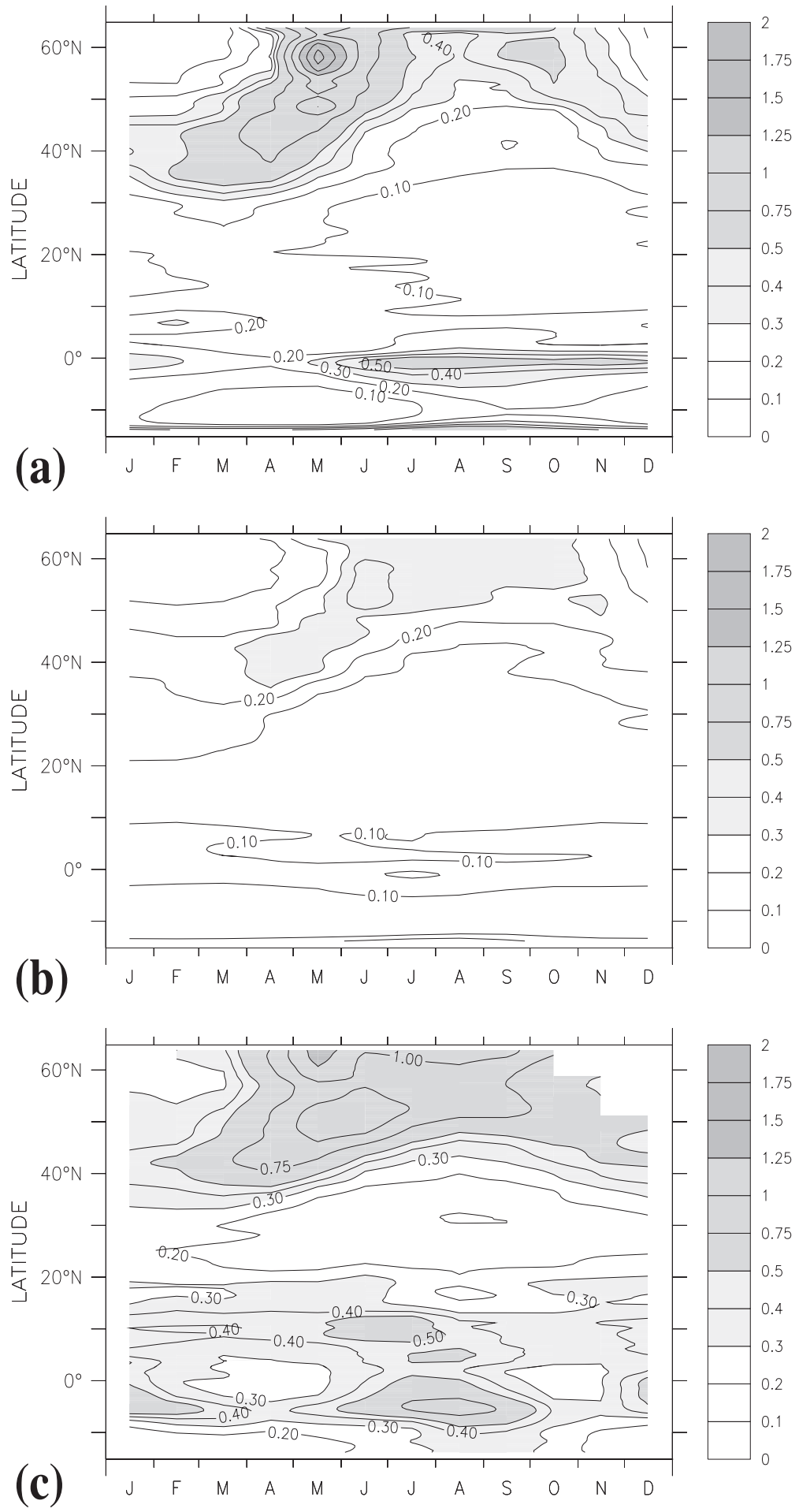

Figure 10. Zonally averaged annual cycle of surface chlorophyll, as simulated (a) by the standard model, and (b) by the optimized model. Panel (c) shows the observational estimate derived from SeaWiFS data. Units are $\mathrm{mg} \mathrm{Chl} \mathrm{m}^{-3}$. 
caused by the variable chlorophyll-to-nitrogen ratios employed in the optimized version: North of about $40 \mathrm{~N}$, simulated surface chlorophyll-to-nitrogen ratios vary from about $0.8 \mathrm{mg} \mathrm{Chl}(\mathrm{mmol} \mathrm{N})^{-1}$ in summer and $1.6 \mathrm{mg} \mathrm{Chl}(\mathrm{mmol} \mathrm{N})^{-1}$ in winter. The seasonal cycle of phytoplankton biomass also shows a reduction in amplitude in the optimized model. Zonally averaged surface phytoplankton concentrations are always smaller than $0.5 \mathrm{mmol} \mathrm{N} \mathrm{m}{ }^{-3}$ which is less than half the maximum reached in the standard run. Moreover, the spring bloom simulated by the optimized model peaks later by more than a month compared to the standard run as well as compared to the SeaWiFS data (Fig. 10).

The smaller amplitude of the seasonal cycle and the more sluggish evolution of the spring bloom in mid and high latitude of the optimized model result mainly from two changes in the ecosystem model. Firstly, the maximum growth rate is reduced by $55 \%$ in the optimized version (Table 1). Secondly, the specific mortality rate of phytoplankton is higher in the optimized model. This adds up to a generally slower net growth of phytoplankton, particularly under optimal light and nutrient conditions as often met during the spring bloom.

Reduced maximum phytoplankton growth and the presence of a rapid recycling of nitrogen from phytoplankton back to the DIN compartment produces a considerably slower drawdown of surface nutrients during spring and summer in mid and high latitudes. While in the standard configuration, DIN is depleted essentially everywhere at some stage during the annual cycle and minimum DIN surface concentrations amount to a few mmol m${ }^{-3}$ over large parts of the subpolar North Atlantic (Fig. 11). Obviously, complete depletion of surface nitrate as simulated by the standard experiment is not consistent with the observations, although different compilations and different interpolation schemes generate substantially different results (Figs. 11c and 11d). The presence and approximate spatial extent of nonvanishing minimum nitrate levels are successfully simulated by the optimized model, although simulated minimum concentrations seem to be too high by up to a factor 2 .

\section{Summary}

The performance of a simple four-compartment marine ecosystem model, which had been optimized in a 1D configuration by fitting it to observations at three sites in the North Atlantic simultaneously, has been evaluated in the context of a 3D basin scale ecosystemcirculation model. In a qualitative, and apart from the BATS site also quantitative, agreement with the earlier results of the 1D optimization (SO03a,b), the model-data misfit at the respective optimization sites is generally reduced in the 3D simulation with respect to a previously employed standard model. The model-data misfit is also considerably reduced at the oligotrophic EUMELI site in the southeastern part of the North Atlantic subtropical gyre. Because none of the EUMELI data had entered the optimization process, they provide a truly independent (albeit local) validation data set.

To evaluate the performance of the 3D model on the basin scale, model results are compared to gridded climatological nitrate and surface chlorophyll data sets, as well as to 


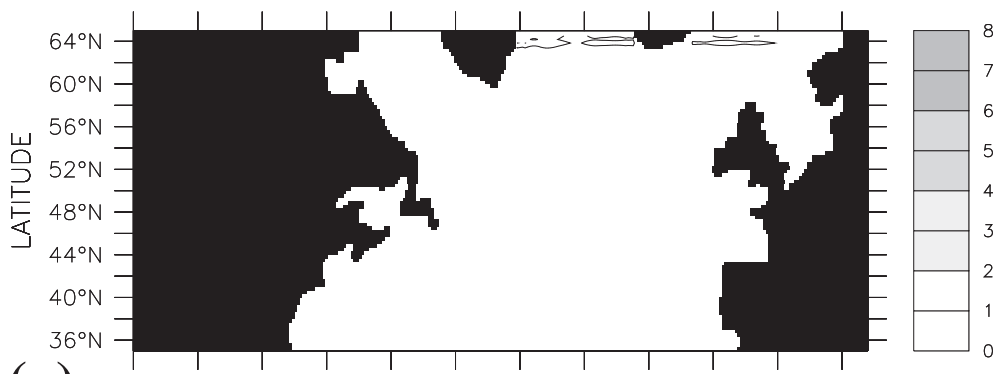

(a) $100^{\circ} \mathrm{W} \quad 80^{\circ} \mathrm{W} \quad 60^{\circ} \mathrm{W} \quad 40^{\circ} \mathrm{W} \quad 20^{\circ} \mathrm{W} \quad 0^{\circ} \mathrm{E}$

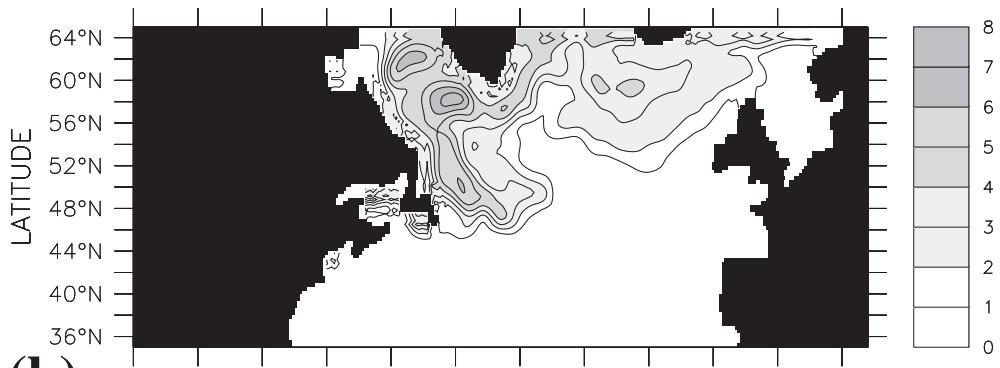

(b) $100^{\circ} \mathrm{W} \quad 80^{\circ} \mathrm{W} \quad 60^{\circ} \mathrm{W} \quad 40^{\circ} \mathrm{W} \quad 20^{\circ} \mathrm{W} \quad 0^{\circ} \mathrm{E}$

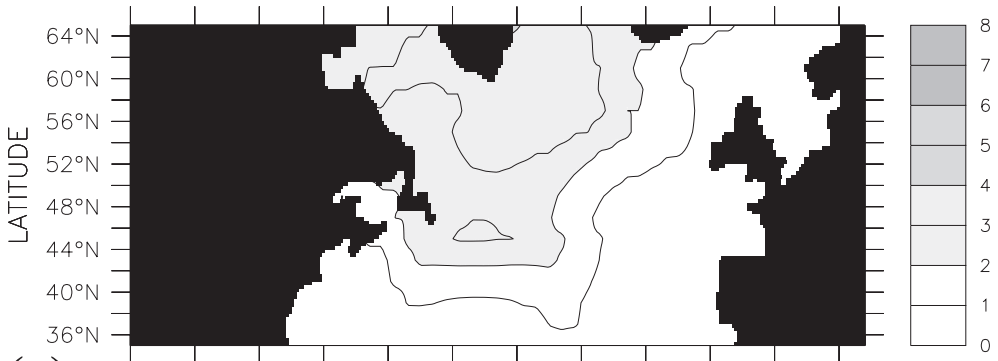

(C) $100^{\circ} \mathrm{W} \quad 80^{\circ} \mathrm{W} \quad 60^{\circ} \mathrm{W} \quad 40^{\circ} \mathrm{W} \quad 20^{\circ} \mathrm{W} \quad 0^{\circ} \mathrm{E}$

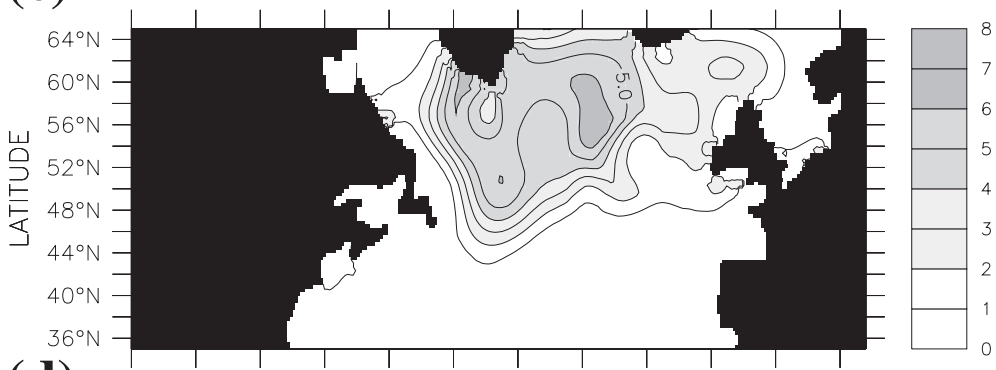

(d) $100^{\circ} \mathrm{W} \quad 80^{\circ} \mathrm{W} \quad 60^{\circ} \mathrm{W} \quad 40^{\circ} \mathrm{W} \quad 20^{\circ} \mathrm{W} \quad 0^{\circ} \mathrm{E}$

LONGITUDE

Figure 11. Minimum surface nitrate concentration reached during the annual cycle for (a) the standard configuration, (b) the optimized model, (c) for monthly mean climatological data compiled by Louanchi and Najjar (2000), and (d) for seasonal mean climatological data compiled by Conkright et al. (1998). Nonvanishing concentrations near the northern boundary in (a) reflect the 1.5 degree wide restoring zone in which nitrate is relaxed against the climatological data of Conkright et al. (1994). 
satellite-derived estimates of primary production. For nitrate, model-data misfits are generally smaller for results of the optimized model run. However, even for the optimized model results it is evident that deviations from the gridded data remain larger than the expected observational, sampling, or mapping errors. The picture is less clear for chlorophyll, for which differences between different data sets are of similar size as model-data differences. A comparison of the seasonal cycle of surface chlorophyll reveals the systematic underestimation of the amplitude of the seasonal cycle over mid and high latitudes as well as a too slow evolution of the spring bloom in the optimized model. At the same time simulated surface DIN does, quite realistically, not become depleted over large areas of the subpolar North Atlantic.

The property that shows the most pronounced improvement in the optimized version with respect to the earlier standard model is depth-integrated annual primary production (Fig. 4). Much of this improvement results from a change in the model structure suggested by Doney et al. (1996) for a 1D model run at BATS, namely the inclusion of a rapid recycling path from phytoplankton directly back to the DIN compartment. This structural change had been tested in an earlier 3D study without the help of data assimilation methods and was shown to lead to much higher, and more realistic, levels of vertically integrated primary production in the subtropical gyre (Oschlies, 2001). An evaluation of the results of this earlier, subjectively tuned model of Oschlies (2001) reveals, however, that there is little to no improvement in the local model-data misfit at the three sites: BATS, NABE, and OWSI (Table 2). While the subjective tuning of the ecosystem model could successfully fix one prominent model deficiency (i.e., the much too low primary production in the oligotrophic subtropical gyre), only the more elaborate model calibration by data assimilation (as performed by SO03a) can actually reduce the overall model-data misfits. Note that in spite of the improvement in integrated annual primary production rates, we may still find systematic model discrepancies in the time-depth distribution of primary production, especially when it comes to the comparison of ${ }^{14} \mathrm{C}$-incubation measurements with model results (see the more detailed discussion in $\mathrm{SO} 03 \mathrm{~b}$ ).

For our ability to model the distribution and transport of biogeochemical tracers it seems encouraging that the export of particulate organic matter (Fig. 3) varies much less between the two model versions than does primary production (Fig. 4). This indicates that the export of organic matter and the balancing input of new inorganic nutrient are to a large extent controlled by the ocean physics (Oschlies, 2001). Note, however, that this strong control by the circulation might be less relevant in those parts of the ocean that exhibit high nutrient concentrations all year round, e.g., the equatorial Pacific or the Southern Ocean. In those areas, errors in our ecosystem models may be more relevant for simulated new and export production than this North Atlantic model study suggests.

\section{Conclusions}

The general improvement of the 3D model calibrated through 1D data assimilation in a nominally objective way (the actual choice of the cost function will always introduce some 
subjectivism) is less striking than we had originally hoped. The large remaining misfits suggest that 1D optimizations, which assume the model physics to be correct, will not automatically help to significantly improve ecosystem models coupled to present basin- or global-scale circulation models. One major problem is errors in the physical model component that the optimization tries to correct by changing the parameters of the ecosystem model. A second major issue is that the parameterizations, equations, or even the entire model structure and the way we partition complex ecosystem models into a few boxes have clear limitations. To our knowledge, all parameter estimation studies performed so far could not constrain more than 10-20 parameters (or linear combinations of parameters). This indicates that models having more tunable parameters (or degrees of freedom) are too complex to be constrained - or to be falsifiable - by the available data. On the other hand, the fact that at the same time none of the models could achieve a satisfactory fit to the data (e.g., within one standard deviation of the observational errors) suggests that models are too simplistic. This apparent contradiction of too high and too low model complexity indicates that either errors are dominated by the physical model component and cannot be reduced any further by adjustments to the biological model component, or that the structure of present ecosystem models is wrong. Presumably, both error sources act in concert.

As long as the underlying dynamical equations, the equivalent to the Navier-Stokes equations in physical oceanography, are not known, we have to continue being ambitious to identify the principles and equations that govern the biotically mediated cycling of biogeochemical tracers in the ocean. To date, an automated optimization has its limitations as long as errors in the physics and the biological model structure prevail and may even dominate uncertainties in the parameter values. A two-step approach consisting of an initial optimization of the model physics and a subsequent calibration of the ecosystem model component driven by the optimized physics might allow for a more straightforward identification of the respective error sources. For the time being, parameter estimation by data estimation can greatly help to calibrate marine ecosystem models and to "objectively" quantify the quality of different modeling approaches. However, with respect to the overall aim of improving the structure of our currently used ecosystem models, we expect an educated and subjective post-assimilation analysis of the remaining model-data misfits and their statistics to be of greater value than the parameter estimation itself.

Acknowledgments. Surface chlorophyll data were kindly provided by the SeaWiFS project (Code 970.2) and the Goddard Earth Sciences Data and Information Services Center. We would like to thank Robby Toggweiler and an anonymous reviewer for their constructive comments which helped to improve the paper.

\section{APPENDIX}

\section{Ecosystem model equations}

For the standard model, the biological source-minus-sink terms in the respective tracer advection-diffusion equation are given by 


$$
\begin{gathered}
\mathrm{sms}_{\text {stand }}(\mathrm{P})=\bar{J}(z, t, \mathrm{~N}) \mathrm{P}-G(\mathrm{P}) \mathrm{Z}-\mu_{\mathrm{P}} \mathrm{P} \\
\mathrm{sms}_{\text {stand }}(\mathrm{Z})=\gamma_{1} G(\mathrm{P}) \mathrm{Z}-\gamma_{2} \mathrm{Z}-\mu_{\mathrm{Z}} \mathrm{Z}^{2} \\
\mathrm{sms}_{\text {stand }}(\mathrm{D})=\left(1-\gamma_{1}\right) G(\mathrm{P}) \mathrm{Z}+\mu_{\mathrm{P}} \mathrm{P}+\mu_{\mathrm{Z}} \mathrm{Z}^{2}-\mu_{\mathrm{D}} \mathrm{D}-w_{s} \frac{\partial \mathrm{D}}{\partial z} \\
\mathrm{sms}_{\text {stand }}(\mathrm{N})=\mu_{\mathrm{D}} \mathrm{D}+\gamma_{2} \mathrm{Z}-\bar{J}(z, t, \mathrm{~N}) \mathrm{P} .
\end{gathered}
$$

For the optimized model, the respective terms are

$$
\begin{gathered}
\mathrm{sms}_{\mathrm{opt}}(\mathrm{P})=\bar{J}(z, t, \mathrm{~N}) \mathrm{P}-G(\mathrm{P}) \mathrm{Z}-\mu_{\mathrm{P}}(T) \mathrm{P}-\mu_{\mathrm{P}}^{*} \mathrm{P}^{2} \\
\mathrm{sms}_{\mathrm{opt}}(\mathrm{Z})=\gamma_{1} G(\mathrm{P}) \mathrm{Z}-\gamma_{2}(T) \mathrm{Z}-\mu_{\mathrm{Z}} \mathrm{Z}^{2} \\
\mathrm{sms}_{\mathrm{opt}}(\mathrm{D})=\left(1-\gamma_{1}\right) G(\mathrm{P}) \mathrm{Z}+\mu_{\mathrm{P}}^{*} \mathrm{P}^{2}+\mu_{\mathrm{Z}} \mathrm{Z}^{2}-\mu_{\mathrm{D}}(T) \mathrm{D}-w_{s} \frac{\partial \mathrm{D}}{\partial z} \\
\mathrm{sms}_{\mathrm{opt}}(\mathrm{N})=\mu_{\mathrm{D}}(T) \mathrm{D}+\gamma_{2}(T) \mathrm{Z}+\mu_{\mathrm{P}}(T) \mathrm{P}-\bar{J}(z, t, \mathrm{~N}) \mathrm{P} .
\end{gathered}
$$

The daily-mean growth rate $\bar{J}$ is assumed to be the minimum of light- and nutrient-limited growth

$$
\bar{J}(z, t, \mathrm{~N})=\min \left(\bar{J}(z, t), J_{\max } \frac{\mathrm{N}}{k_{1}+\mathrm{N}}\right)
$$

where $\bar{J}(z, t)$ denotes the purely light-limited growth rate computed for a triangular daily shape of incident radiation following Evans and Parslow (1985), and $J_{\max }$ is the lightsaturated growth (see Oschlies and Garçon (1999) for a more detailed description). For zooplankton grazing, a Holling type III function is used:

$$
G(P)=\frac{g \epsilon \mathrm{P}^{2}}{g+\epsilon \mathrm{P}^{2}} .
$$

The individual biological parameter values are given in Table 1 for the two model configurations.

Chlorophyll is diagnosed from simulated nitrogen-based phytoplankton concentrations by a constant conversion rate of $1.59 \mathrm{mg} \mathrm{Chl} / \mathrm{mmol} \mathrm{N}$ in the standard model, and by the empirical fit of Cloern et al. (1995) that relates the chlorophyll-to-carbon ratio to light and temperature in the optimized version.

\section{REFERENCES}

Antoine, D., J.-M. André and A. Morel. 1996. Oceanic primary production 2. Estimation at global scale from satellite (coastal zone color scanner) chlorophyll. Global Biogeochem. Cycles, 10, 57-69.

Aumont, O., J. C. Orr, P. Monfray, G. Madec and E. Maier-Reimer. 1999. Nutrient trapping in the equatorial Pacific: The ocean circulation solution. Global Biogeochem. Cycles, 13, 351-369.

Christian, J. R., M. A. Verschell, R. Murtugudde, A. J. Busalacchi and C. R. McClain. 2002. 
Biogeochemical modelling of the tropical Pacific Ocean. I: seasonal and interannual variability. Deep-Sea Res. II, 49, 509-543.

Cloern, J. E., C. Grenz and L. Vidergar-Lucas. 1995. An empirical model of the phytoplankton chlorophyll: carbon ratio- the conversion factor between productivity and growth rate. Limnol. Oceanogr., 40, 1313-1321.

Conkright, M. E., S. Levitus and T. P. Boyer. 1994. World Ocean Atlas 1994, Vol. 1: Nutrients. NOAA Atlas NESDIS 1, U.S. Gov. Print. Office, Washington, D.C., 162 pp.

Conkright, M. E., S. Levitus, T. O’Brien, T. P. Boyer, C. Stephens, D. Johnson, L. Stathoplos, O. Baranova, J. Antonov, R. Gelfeld, J. Burney, J. Rochester and C. Forgy. 1998. World Ocean database 1998, CD-ROM Data Set Documentation. O.C.L., National Oceanographic Data Center Internal Report 14, $111 \mathrm{pp}$.

Conkright, M. E., T. D. O’Brien, C. Stephens, R. A. Locarnini, H. E. Garcia, T. P. Boyer and J. I. Antonov. 2002. World Ocean Atlas 2001, Volume 6: Chlorophyll. S. Levitus, ed., NOAA Atlas NESDIS 54, U.S. Government Printing Office, Wash., D.C., 46 pp.

Doney, S. C., D. M. Glover and R. G. Najjar. 1996. A new coupled, one-dimensional biologicalphysical model for the upper ocean: Application to the JGOFS Bermuda Atlantic Time series Study (BATS) site. Deep-Sea Res. II, 43, 591-624.

Evans, G. T. and J. S. Parslow. 1985. A model of annual plankton cycles. Biol. Oceanogr., 3, $328-347$.

Fasham, M. J. R., H. W. Ducklow and S. M. McKelvie. 1990. A nitrogen-based model of plankton dynamics in the oceanic mixed layer. J. Mar. Res., 48, 591-639.

Fasham, M. J. R. and G. T. Evans. 1995. The use of optimisation techniques to model marine ecosystem dynamics at the JGOFS station at 47N 20W. Phil. Trans. Roy. Soc. Lond. B, 348, 203-209.

Fennel, K., M. Losch, J. Schröter and M. Wenzel. 2001. Testing a marine ecosystem model: sensitivity analysis and parameter optimization. J. Mar. Syst., 28, 45-63.

Gaspar, P., Y. Gregoris and J.-M. Lefevre. 1990. A simple eddy kinetic energy model for simulations of the oceanic vertical mixing: tests at station Papa and long-term upper ocean study site. J. Geophys. Res., 95, 16,179-16,193.

Gibson, J. K., P. Kallberg, S. Uppala, A. Hernandez, A. Nomura and E. Serrano. 1997. ECMWF Re-Analysis Project Report Series. 1. ERA Description, European Centre for Medium-Range Weather Forecasting, Reading UK, 72 pp.

Hurtt, G. C. and R. A. Armstrong. 1996. A pelagic ecosystem model calibrated with BATS data. Deep-Sea Res. II, 43, 653-683.

1999. A pelagic ecosystem model calibrated with BATS and OWSI data. Deep-Sea Res. I, 46, 27-61.

Ledwell, J. R., A. J. Watson and C. S. Law. 1993. Evidence for slow mixing across the pycnocline from an open-ocean tracer-release experiment. Nature, 364, 701-703.

1998. Mixing of a tracer in the pycnocline. J. Geophys. Res., 103, 21,499-21,529.

Levitus, S. and T. Boyer. 1994. World Ocean Atlas 1994, Vol. 4: Temperature. NOAA Atlas NESDIS 4, U.S. Gov. Print. Office, Washington, D.C., 99 pp.

Levitus, S., R. Burgett and T. P. Boyer. 1994. World Ocean Atlas 1994, Vol. 3: Salinity. NOAA Atlas NESDIS 3, U.S. Gov. Print. Office, Washington, D.C., 99 pp.

Longhurst, A. 1998. Ecological Geography of the Sea, Academic Press, San Diego, 398 pp.

Louanchi, F. and R. G. Najjar. 2000. A global monthly mean climatology of phosphate, nitrate and silicate in the upper ocean: Spring-summer production and shallow remineralization. Global Biogeochem. Cycles, 14, 957-977.

Matear, R. J. 1995. Parameter optimization and analysis of ecosystem models using simulated annealing: A case study at Station P. J. Mar. Res., 53, 571-607. 
Matear, R. J. and G. Holloway. 1995. Modeling the inorganic phosphorus cycle of the North Pacific using an adjoint data assimilation model to assess the role of dissolved organic phosphorus. Global Biogeochem. Cycles, 9, 101-119.

Morel, A. 2000. Process studies in eutrophic, mesotrophic, and oligotrophic oceanic regimes within the tropical northeast Atlantic, in The Changing Ocean Carbon Cycle, R. B. Hanson, H. W. Ducklow and J. G. Field, eds., IGBP book series, 5, Cambridge University Press, 338-374.

Najjar, R. G., J. L. Sarmiento and J. R. Toggweiler. 1992. Downward transport and fate of organic matter in the ocean: simulations with a general circulation model. Global Biogeochem. Cycles, 6 , 45-76.

Oschlies, A. 2000. Equatorial nutrient trapping in biogeochemical ocean models: the role of advection numerics. Global Biogeochem. Cycles, 14, 655-667.

2001. Model-derived estimates of new production: New results point towards lower values. Deep-Sea Res. II, 48, 2173-2197.

2002. Can eddies make ocean deserts bloom? Global Biogeochem. Cycles, 16, 1106, doi:10.1029/2001GB001830.

Oschlies, A. and V. Garçon. 1999. An eddy-permitting coupled physical-biological model of the North Atlantic. Part I: Sensitivity to advection numerics and mixed layer physics. Global Biogeochem. Cycles, 13, 135-160.

Oschlies, A., W. Koeve and V. Garçon. 2000. An eddy-permitting coupled physical-biological model of the North Atlantic. Part II: Ecosystem dynamics and comparison with satellite and JGOFS local studies data. Global Biogeochem. Cycles, 14, 499-523.

Prunet, P., J. F. Minster, D. Ruiz-Pino and I. Dadou. 1996a. Assimilation of surface data in a one-dimensional physical-biogeochemical model of the surface ocean. 1. Method and preliminary results. Global Biogeochem. Cycles, 10, 111-138.

Prunet, P., J. F. Minster, V. Echevin and I. Dadou. 1996b. Assimilation of surface data in a one-dimensional physical-biogeochemical model of the surface ocean. 2. Adjusting a simple trophic model to chlorophyll, temperature, nitrate and $\mathrm{P}_{\mathrm{CO}_{2}}$ data. Global Biogeochem. Cycles, 10, 139-158.

Sarmiento, J. L., R. D. Slater, M. J. R. Fasham, H. W. Ducklow, J. R. Toggweiler and G. T. Evans. 1993. A seasonal three-dimensional ecosystem model of nitrogen cycling in the North Atlantic euphotic zone. Global Biogeochem. Cycles, 7, 417-450.

Schartau, M. and A. Oschlies. 2003a. Simultaneous data-based optimization of a 1D-ecosystem model at three locations in the North Atlantic: Part I-Method and parameter estimates. J. Mar. Res., 61, 765-793.

- 2003b. Simultaneous data based optimization of a 1D-ecosystem model at three locations in the North Atlantic: Part II-Standing stocks and nitrogen fluxes. J. Mar. Res., 61, 795-821.

Schartau, M., A. Oschlies and J. Willebrand. 2001. Parameter estimates of a zero-dimensional ecosystem model applying the adjoint method. Deep-Sea Res. II, 48, 1769-1800.

Spitz, Y. H., J. R. Moisan and M. R. Abbott. 2001. Configuring an ecosystem model using data from the Bermuda Atlantic Time Series (BATS). Deep-Sea Res. II, 48, 1733-1768.

Spitz, Y. H., J. R. Moisan, M. R. Abbott and J. G. Richman. 1998. Data assimilation and a pelagic ecosystem model: parameterization using time series observations. J. Mar. Syst., 16, 51-68.

Taylor, K. E. 2001. Summarizing multiple aspects of model performance in a single diagram. J. Geophys. Res., 106(D7), 7183-7192.

Williams, R. G. and M. J. Follows. 1998. The Ekman transfer of nutrients and maintenance of new production over the North Atlantic. Deep-Sea Res. I, 45, 461-489. 